\title{
Intention to stop khat chewing and associated factors among khat chewers in Gondar city, northwest Ethiopia: using Trans Theoretical Model
}

\section{Asmamaw Adugna}

University of Gondar College of Medicine and Health Sciences

Telake Azale

University of Gondar College of Medicine and Health Sciences

Simegnew Handebo ( $\square$ hsimegnew@yahoo.com )

University of Gondar https://orcid.org/0000-0002-0166-5560

\section{Research}

Keywords: Intention to stop, khat, Transtheoretical model, Gondar

Posted Date: March 3rd, 2020

DOI: https://doi.org/10.21203/rs.2.24264/v2

License: (c) (i) This work is licensed under a Creative Commons Attribution 4.0 International License.

Read Full License 


\section{Abstract}

Background Khat chewing practice is rapidly increasing worldwide and currently an estimated over 10 million people chew khat. Trans Theoretical Model (TTM) is a promising model to assess the of stages of behavior change is a combination of intention. Given a sufficient control over the behavior, people carry out their intentions when the enabling environments arises. Assessing intention to quit chewing khat, motivational factors that influence behavior, is important to design effective interventions.

Methods Community-based cross-sectional study was conducted from March to April 2019 in Gondar city, northwest Ethiopia. Six hundred five khat chewers were selected from six kebeles using cluster sampling method. Structured interviewer-administered questionnaire was used to collect data. Bivariate and multi-variable logistic regression model were fitted. Adjusted Odds ratio (AOR) with $95 \%$ confidence interval and $p$-values $<0.05$ in the multi-variable model were used to declare significant association.

Results Out of the total participants, $69.3 \%$ (95\% Cl: 65.8-72.9) had intention to stop khat chewing within six months from the day of interview or before. Majority of the study participants $55.4 \%$ were on contemplation stage. Higher self-reevaluation [AOR=2.8, $(95 \% \mathrm{Cl}: 1.6-5.0)]$, environmental reevaluation [AOR=1.9, (95\% Cl: 1.1-3.3)] and social liberation [AOR=1.8, (95\% Cl: 1.0-3.1)] process of changes were associated with intention to quit khat chewing. In addition, using additional substances and start chewing at earlier age were associated with lower intention to quit chewing.

Conclusion Majority of the khat chewers had the intention to stop khat chewing. Increased selfreevaluation, environmental reevaluation and social liberation process of changes enhance the intention of quitting khat chewing. Thus, stage-based interventions should be done to motivate Khat chewers to stop khat chewing.

\section{Introduction}

Khat (Catha edulis) is an evergreen plant that grows at high altitudes between 1500-2000 meters above sea level. It commonly grows throughout the year in the Horn of African or Middle East countries. Khat leaves has been used as a stimulant for recreational purposes for centuries in the Horn of Africa and the Arabian Peninsula [1-6]. It also used for social and religious purposes [7]. Khat contains psychoactive ingredients which effect individual's consciousness, behavior, mood and thinking processes [8]. These active ingredients have a potential to lead physical and psychological dependence [1, 7-9]. However, chewers believe that it would keep them alert, attain greater concentration, boosts pleasure, and enhances motivation [9].

In Ethiopia, chewing of khat is becoming habitual and increasing at an alarming rate, especially in the younger segment of the population. A meta-analysis on the prevalence of khat chewing among university students in Ethiopian indicated that above one in five students have been engaged in chewing khat [10]. According to the 2016 Ethiopia Demographic and Health Survey (EDHS) report 12\% of women and 27\% of men respondents reported ever chewed khat and of which two in three chewed chat for 6 or more days 
in the last 30 days preceding the survey. Khat consumption varies widely across by regions (highest in Harari and lowest in Tigray), education and wealth status [11].

However, khat use has multiple serious medical, sexual, economic and psychosocial problems. Long-term khat chewing resulted in mental and neurological aberrations such as cognitive impairment, learning problems and behavioral abnormalities. It also accounts for gastrointestinal tract problems like esophagitis, gastritis, and a delay in intestinal absorption. Moreover, it is associated with dental, cardiovascular, genitourinary problems and myocardial infarction [12-16]. Khat chewing may harm the economy by the loss in production as a result of laziness and absenteeism. Workers go to lunch and engage in Khat sessions, and do not return to work [17].

A qualitative study among khat quitter in Saudi revealed the deciding to quit khat chewing is often due to multiple reasons. The most common reasons were feeling of guilty for giving up prayers, feeling lost and neglecting family, accumulation of debts, work neglect and frequent absenteeism, and impaired health [17]. Similarly, Transtheoretical Model (TTM) assume that people do not change behaviors quickly and decisively and an individual will remain stuck in the early stages of behavioral change. Rather, change in behavior, especially habitual behavior, occurs continuously through a cyclical process [18].

Empirical evidences support the transtheoretical model as the dominant model of health behavior change. The TTM is aimed at understanding an individual's readiness to act on a new healthier-behavior and describing how people move through five different stages of behavioral changes. The four core constructs of TTM are stages of change, self-efficacy, decisional balance, and processes of change. The model indicates that individuals who were attempting to change their health behavior might experience a series of stages of readiness for change, namely: precontemplation, contemplation, preparation, action, and maintenance. Movement through these stages often occurs in cyclic rather than linear patterns. In moving through these stages of change, people apply cognitive, affective, and evaluative processes [19].

The current study focuses on assessing the intention to stop khat chewing among chewers using TTM. Intentions to stop khat chewing can be conceptualized as a readiness to engage in the quitting process [20]. Although, the use of intentions to predict behavior was controversial [21], evidences recognize that behaviors can be predicted by assessing intentions to engage in the behaviors under consideration [20]. Intentions have less impact on behavior when participants lack control over the behavior, when there is potential for social reaction, and when circumstances of the performance are conducive to habit formation [22]. It is assumed that the intention-behavior gap mediated by planning, maintenance selfefficacy and control of action. We expect that the higher the intention, the more likely it is that the behavior will in fact be performed [21,23]. Theory based measurement of behavior changes is important to organize our thinking about the health problem as well as development and refinement of interventions. Despite numerous studies on the prevalence of khat were conducted in Ethiopia, quitting and intention to quit khat chewing area were not well-investigated in Ethiopia. So, this study aimed at assessing the intention to stop khat chewing and associated factors among chat chewers in Gondar city, northwest Ethiopia. 


\section{Methods}

\section{Study setting and design}

Community-based cross-sectional study was conducted from March 15 to April 14, 2019 in Gondar, northwest Ethiopia. Gondar City is found in central Gondar zone of Amhara regional state located $727 \mathrm{~km}$ North West of Addis Ababa. There are 21 administrative kebeles with estimated total population of $338,746(160,522$ male \& 178,223 female) [24]. The city is found 2,133 meter above mean sea level with annual rainfall up to 1200 cubic millimeter. In the city there are 160 licensed and functional khat chewing houses and shops [25].

\section{Study population and sample size}

All khat chewers eighteen and above years old and who lived in the city at least for six months were included in the study. Overall, 605 khat chewers who chewed khat for the last one month before the survey were interviewed in the study. The study participants were recruited by cluster sampling method from randomly selected six kebeles/clusters. A total of 32 khat chewing houses and shops is the selected kebeles were included in the study. The sample proportionally allocated to each chewing houses and shops.

\section{Data collection procedures}

Structured and translated to Amharic (local language) questionnaire adopted from TTM tool was used to collect the data [26-28]. The questionnaire was also pretested on 5\% (32 participants) in Teda town. The reliability test of Cronbach's alpha ranged from 0.74 for khat dependency to 0.86 for self-reevaluation. With the supervision of two supervisors and principal investigator, questionnaires were filled by 6 BSc degree holder Nurses. Intensive training was given to the data collectors and supervisors on the research tool, purpose of the study, interviewing techniques and handling of ethical issues by the primary investigator.

\section{Measurement}

From TTM stages of changes the first three stages (pre-contemplation, contemplation and preparation) were relevant to measure intention. Pre-contemplators were chewers who were not seriously thinking about quitting khat chewing in the next 6 months. Contemplators were the chewers who reported that they were thinking about quitting in the next 6 months but not in the next 30 days. Whereas, preparator chewers who were planning to quit in the next 30 days and had made a quit attempt in the last year. In addition to socio-demographic variable and chewing history, five dimensions of process of change of chewing khat: consciousness raising, dramatic relief, environmental re-evaluation, social liberation, and self-reevaluation. Twenty Likert scale questions ( $1=$ Strongly Disagree 2= Disagree 3=Neutral 4= Agree 5= Strongly Agree) were used to assessed. The mean score of the five dimensions were re-coded as low $(<3)$, medium (3) and high ( $>3$ ). 
Self-efficacy, the confidence that individuals can manage temptations for not chewing khat, was measured by twenty Likert scale questions ( $1=$ Not Very Confident $2=$ Not Confident $3=$ Neutral $4=$ Confident $5=$ Very Confident) and categorized as having low, intermediate and high self-efficacy if they had mean score of $<3,3$ and $>3$ respectively. Decisional balance is the balance between the perceived advantages of chewing khat and the perceived disadvantages of chewing khat was measured by 18 Likert scale items ( 9 items for each) ( $1=$ Strongly Disagree $2=$ Disagree $3=$ Neutral $4=$ Agree $5=$ Strongly agree) and the total score was re-coded as positive, undecided and negative. Self-reported khat dependence, level of khat dependence, was measured by 10 Likert items questions ( $1=$ Strongly Disagree 2= Disagree 3= Neutral 4= Agree 5= Strongly agree) and total score was recoded as low, medium and high dependence for a total score of $<3,3$ and $>3$ respectively $[26,29]$.

\section{Data processing and analysis}

Data were entered in the EPI - info version7 statistical software and exported to SPSS version 20 statistical package for analysis. Descriptive statistics analysis was done to see the distribution of sociodemographic characteristics, process of change and intention to quit khat chewing. After bivariable analysis was done, variables with $p$-values of $<0.2$ were entered into a multivariable logistic regression model to identify predictors associated with intention to quite khat chewing. These factors were expressed by AOR with $95 \% \mathrm{Cl}$ and a probability value of type -1 error less of less than 0.05 was considered statistically significant.

\section{Results}

\section{Socio demographic characteristics}

Of the 634 selected participants 605 were successfully interviewed, with a response rate of $95.4 \%$. Five hundred three (83.1\%) were males. The median age of the respondents was 27 years (23 and 34 year were the 1 st and 3rd quartiles respectively). With regard to educational status 270 (44.6\%) attended diploma and above. Majority 384 (63.5\%) of them were single. Above one in every four $(26.9 \%)$ of the study participants had no job (Table 1).

\section{Stages of change}

Out of the total participants, 417 (69.3\%) (95\% Cl: 65.8-72.9) have an intention to stop khat chewing at least within the next six months. Majority of the study participants $335(55.4 \%)$ were on contemplation stage.

\section{Processes of change and self-efficacy}

The mean score of the process of change of the participant increased from precontemplation to the preparation stage. Nearly half of the participant had low consciousness raising $(48.3 \%)$ and high dramatic relief (46.8\%) score. Majority of them had high self-reevaluation $(60.3 \%)$ social liberation $(53.4 \%)$ and environmental reevaluation (62.5\%) scores. The respondent's self-efficacy to stop khat 
chewing revealed that half (50.9\%) had low self-efficacy and 276 (45.6\%) had low self-efficacy. Only $21(3.5 \%)$ of them had medium self-efficacy to stop khat chewing (Table 2).

\section{Decisional balance to stop khat chewing}

This study found that for majority $(57.4 \%)$ of the respondent, the mean score of cons (costs) of khat chewing was higher than the pros (benefit) score (negative decisional balance). On the other hand, for $38.3 \%$ of them, the mean score of pros of khat chewing was higher than the cons (positive decisional balance) and $26(4.3 \%)$ of respondents were undecided (Table 2 ).

\section{Khat dependency and chewing history}

From total respondents, $263(43.5 \%)$ had high khat dependence and whereas, $310(51.2 \%)$ of the total respondents had low dependency. The mean age for initiation of Khat chewing was $20.42(S D \pm 4.3)$ years. The mean duration of Khat chewing was $8.67(\mathrm{SD} \pm 6.5)$ years. Two hundred thirty $(38.0 \%)$ of the participants chewed khat for 4.39 (SD \pm 2.6$)$ hours per week. With regard to the purpose of chewing most of the participants 317 (52.4\%) chewed khat for recreation and 129 (21.3\%) for reading. For about threefourth $447(73.9 \%)$ of the participants, khat chewing was a mean of social interaction. Chewing was combined with cigarette smoking for 220 (36.4\%) and alcohol drinking for 170 (28.1\%) participants.

\section{Factors associated with intention to stop khat chewing}

As indicated in Table 3, in multivariable analysis age at start to chew, frequency of additional drug use, environmental reevaluation, self-reevaluation and social liberation variables were significantly associated with intention to stop khat chewing. The odds of intention to stop khat chewing increased among adults who started chewing at older age compared to those who start chewing at early age. Adults who started chewing khat in age group 16-20 years [AOR=3.2, (95\% Cl; 1.5-6.9)], 21-25 years [AOR=2.8, (95\% Cl; 1.16.9)], and older than 26 years [AOR=4.8, (95\% Cl; 1.5-15.5)] had higher odds of intention to stop khat chewing as compared to those who started chewing at age fifteen and below. The odds of intention to stop khat chewing among adults who use additional substances (cigarette, hashish, alcohol) daily $63 \%$ than those who use sometimes [AOR=0.37, $(95 \% \mathrm{Cl} ; 0.16-0.85)$ ]. Adults who had high environmental reevaluation score were about 2 times more likely to have the intention to stop chewing than those who had low environmental reevaluation [AOR=1.9, (95\% Cl: 1.1-3.3)]. Khat chewers who had high selfreevaluation score were 3 times more likely to have the intention to stop chewing than those who had low self-reevaluation [AOR=2.8 (95\% Cl: 1.6-5.0)]. Participants who had high social liberation score were about 2 times more likely to have intention to stop khat chewing than those with low social liberation score [AOR=1.8, (95\% Cl: 1.0-3.1)]. Respondents who had high khat dependence were $39 \%$ less likely to have intention to stop khat chewing as compared to those low khat dependence [AOR=0.61, $(95 \% \mathrm{Cl}$ : 0.38 0.99)].

\section{Discussion}


Despite studies on the prevalence of khat chewing, intention to stop and quitting khat chewing will be an input for policy makers and programmers to plan appropriate interventions at different level. This study revealed that $(69.3 \%)(95 \% \mathrm{Cl}: 65.8-72.9)$ of participants had an intention to stop khat chewing within the next six months or before. This result was consistent with other study conducted in Dessie city (Ethiopia) [26]. On the other hand, our finding was higher than the result of other studies done in Saudi Arabia (29.5\%) [30], male Yemeni adults' resident in UK (46\%) [31] and UK (55\%) [32]. This could be due to difference in socio-demographic characteristics among study population. Another reason could be the difference in the way intention to quite khat chewing was measured. Intention to quit khat chewing was measured by asking "Are you able to stop using Khat when you want to?" in Saudi Arabia and "Did you want stop chewing khat?" in Yemeni and UK study. While our study intention was measured by using the staging algorithm developed by Prochaska, Diclemente, and colleagues (contemplation and preparation stages) [18].

The mean age for initiation of Khat chewing was 20.42 (SD \pm 4.3 ) years. This finding is similar with those studies done at Dessie (Ethiopia) [26], Saudi Arabia [30], and UK [32]. However, it was higher than study done among Yemeni adults in UK [31]. In this study, adults who started chewing at older age had increased odds of intention to stop khat chewing than who start chewing at early age. The fall in the age of initiation of khat chewing enable adults to have prolonged exposure for khat which enhance their khat dependence level. This could be due to extended khat chewing period (among those who started to chew at age of 15 year and below) leads to less likely to intend to stop khat chewing. Similarly, this study also found that intention to stop khat chewing was lower among chewers who had high levels of khat dependence. This is consistent with a study done in Saudi Arabia that reported majority of respondents were not intended to stop khat chewing potentially due to dependence. On the other hand, this also indicates the gaps of prevention strategies on substance abuse in general and khat use in particular [30].

According to this study, individuals who use additional drugs daily (cigarette, hashish, alcohol) have lower intention to stop khat chewing. The concurrent substance use is a barrier of quitting and intention to quit since using one would tempt them to the use of others. Inline to this, systematic review and metaanalysis among Ethiopian university students revealed alcohol drinking and cigarette smoking were the predictors of khat chewing [10]. This finding was consistent with a qualitative study done among khat users and healthcare professionals in London [33]. In-contrast, the study done among khat quitters in the Jazan area of Saudi Arabia unable to relate khat use or quitting to other drugs use [14].

In TTM the processes of change are the covert and overt activities that people use to progress through stages of changes. The participant who use the process of changes have an intention to stop khat chewing. The study revealed that the participant who had high environmental reevaluation, selfreevaluation and social liberation more likely intend to quit khat chewing than their counterparts. Environmental reevaluation is realizing the negative impact of the khat chewing on one's social and/or physical environment $[34,35]$. According to our study, adults who had high environmental reevaluation score had 2 times increased odds to have the intention to stop khat chewing compared to those who had low environmental reevaluation. Similarly, individuals at high social liberation process of change were 2 
times more likely to have the intention to stop khat chewing than Khat chewers at low social liberation process of change. Self-liberation is realizing that the social norms are changing in the direction of supporting the healthy behavior change $[34,35]$. This finding is inconsistent with studies done in on Dessie town, which showed medium environmental reevaluation and social liberation process of change was associated with increased intention to stop khat chewing [26] and Dire Dawa town, that revealed no difference between high, medium and low environmental reevaluation and social liberation process of change with intention to quitting smoking [29]. The possible reason might be difference in socio-cultural and demographic factors between the study areas.

On the other hand, individuals with high were 3 times more likely to have the intention to stop khat chewing than those with low self-reevaluation. Self-reevaluation is realizing that the behavior change is an important part of one's identity $[34,35]$. This result is consistent with study done in Dire Dawa town [29] and whereas, differ from study done in Dessie town. The observed difference might be due to socio cultural variation between the study populations. Other variables in TTM like, consciousness raising, dramatic relief, self-efficacy and decisional balance were not significant predictors of intention to stop khat chewing.

\section{Limitation Of The Study}

There are a few limitations of this study. First, in the TTM the lines between the stages can be arbitrary with no set criteria for how to determine a person's stage of change. Second, since khat chewing behavior is sensitive there may be social desirability that overestimate the intention to quite chewing. Being a cross-sectional study may not allow establishing to draw causal relationships among the variables.

\section{Conclusion}

Majority of the khat chewers had the intention to stop khat chewing at least within the next six months. Age at start to chewing, daily use of additional drug, khat dependency, environmental reevaluation, selfreevaluation and social liberation were significant predictors of intention to stop khat chewing. Thus, stage-based interventions should be taken to personalized risk, alter risk perception, value clarification, and clarify misconceptions. In addition to intervention to decrease substance abuse, skill trainings and modelling (who have previously overcome difficult barriers) need to be emphasized to enhance khat chewers intention to stop chewing.

\section{Abbreviations}

AOR

Adjusted Odds Ratio, Cl:Confidence Interval, EDHS:Ethiopia Demographic and Heath Surveys; SD:Standard Deviation, SPSS:Statistical Package for Social Science, TTM:Trans Theoretical Model

\section{Declarations}




\section{Ethics approval and consent to participate}

Ethical clearance letter No.180/2019 was obtained from the Institutional Review Board of the University of Gondar Institute of Public Health. Oral consent also obtained from owners of khat chewing houses and shops. After the objective and aim of the study have been informed oral consent was obtained from study participants. The confidentiality and anonymity of participant's information kept. Individual identifiers were excluded and the data were stored in a locked computer. Health information was given for participant about the effect of khat by data collectors.

\section{Consent for publication}

Not applicable

\section{Availability of data and materials}

The datasets underlying the findings are available from the corresponding author and would be available without restriction if the manuscript is published.

\section{Competing interests}

The authors declare that they have no conflict of interest

\section{Funding}

The authors received no specific funding for this work

\section{Authors' contribution}

AA conceived the study, coordinated data collection, and carried out the statistical analysis and drafted the manuscript. TA SH participated in the drafting research, statistical analysis, and review the drafted the manuscript. All authors read and approved the final manuscript.

\section{Acknowledgement}

We would like to thank the study participants for their willingness to participate in the study. Our appreciation will also go to the data collectors.

\section{Authors' detail}

'Department of Health Education and Behavioral Sciences, Institute of Public Health, College of Medicine and Health Sciences, University of Gondar, Gondar, Ethiopia.

\section{References}

1. Kalix P (1992) Cathinone, a natural amphetamine. Pharmacol Toxicol 70: 77- 86. 
2. Al-Mugahed, Leen. Khat chewing in Yemen: turning over a new leaf. Bulletin of the World Health Organization. 2008; 741-742.

3. Brooke C. Khat (Catha edulis): its production and trade in the Middle East. The Geographical Journal. 1960 Mar 1;126(1):52-9.

4. Corkery JM, Schifano F, Oyefeso A, Ghodse AH, Tonia T, Naidoo V, Button J. Overview of literature and information on" khat-related" mortality: a call for recognition of the issue and further research. Annali dell'Istituto superiore di sanitÃ. 2011;47:445-64.

5. Manghi RA, Broers B, Khan R, Benguettat D, Khazaal Y, Zullino DF. Khat use: lifestyle or addiction?. Journal of psychoactive drugs. 2009 Mar 1;41(1):1-0.

6. David MA, Neil CMC. Khat: Social harms and legislation: A literature review. home office 2011

7. Hussain.M Aa. Health and Soci-economic Hazard associated with Khat consumption $\mathrm{J}$ from community med. 2013;15(1):3-11.

8. Wabe NT. Chemistry, pharmacology, and toxicology of khat (catha edulis forsk): a review. Addiction \& health. 2011;3(3-4):137.

9. WHO (2004) Neuroscience of psychoactive substances and dependency.

10. Gebrie A, Alebel A, Zegeye A, Tesfaye B. Prevalence and predictors of khat chewing among Ethiopian university students: A systematic review and meta-analysis. PloS one. 2018 Apr 12;13(4):e0195718.

11. CSA I. Central statistical agency (CSA)[Ethiopia] and ICF. Ethiopia demographic and health survey, Addis Ababa, Ethiopia and Calverton, Maryland, USA. 2016.

12. Colzato LS, Ruiz MJ, van den Wildenberg WP, Hommel B. Khat use is associated with impaired working memory and cognitive flexibility. PloS one. 2011 Jun 15;6(6):e20602.

13. al'Absi M, Khalil NS, Al Habori M, Hoffman R, Fujiwara K, Wittmers L. Effects of chronic khat use on cardiovascular, adrenocortical, and psychological responses to stress in men and women. The American Journal on Addictions. 2013 Mar;22(2):99-107.

14. Alsanusy R, El-Setouhy M. Why would khat chewers quit? An in-depth, qualitative study on Saudi Khat quitters. Substance abuse. 2013 Oct 1;34(4):389-95.

15. Al-Habori M. The potential adverse effects of habitual use of Catha edulis (khat). Expert opinion on drug safety. 2005 Nov 1;4(6):1145-54.

16. Al-Motarreb A, Briancon S, Al-Jaber N, Al-Adhi B, Al-Jailani F, Salek MS, Broadley KJ. Khat chewing is a risk factor for acute myocardial infarction: a case-control study. British Journal of clinical pharmacology. 2005 May;59(5):574-81.

17. Ageely HM. Health and socio-economic hazards associated with khat consumption. Journal of family \& community medicine. 2008 Jan;15(1):3.

18. Wayne W. LaMorte, The Transtheoretical Model (Stages of Change); Boston University School of Public Health September 9, 2019. http://sphweb.bumc.bu.edu/otlt/MPHModules/SB/BehavioralChangeTheories/BehavioralChangeTheories6.html accessed January 17, 2020 
19. Prochaska JO, Velicer WF. The transtheoretical model of health behavior change. American journal of health promotion. 1997 Sep;12(1):38-48.

20. Fishbein M. A reasoned action approach to health promotion. Medical Decision Making. 2008 Nov;28(6):834-44.

21. Manski CF. The use of intentions data to predict behavior: A best-case analysis. Journal of the American Statistical Association. 1990 Dec 1;85(412):934-40.

22. Webb TL, Sheeran P. Does changing behavioral intentions engender behavior change? A metaanalysis of the experimental evidence. Psychological bulletin. 2006 Mar;132(2):249.

23. Sniehotta FF, Scholz U, Schwarzer R. Bridging the intention-behaviour gap: Planning, self-efficacy, and action control in the adoption and maintenance of physical exercise. Psychology \& Health. 2005 Apr 1;20(2):143-60.

24. Gondar City health Office 2017/2018 report.(Unpublished document)

25. Gondar City Trade Industry and Market Development 2017/2018 report. (Unpublished document)

26. Minilk E, Telake A, Slassie MG, Getasew A, Belayneh K. Intention to stop Khat chewing and associated factors among Khat chewers in Dessie city, North eastern Ethiopia. Epidemiology: Open Access. 2016;6(3).

27. R W. Finding better ways of motivating and assisting smokers to stop. European Health Psychologist. 2008 10(3):54-8.

28. Velicer WF, DiClemente CC, Prochaska JO, Brandenburg N. Decisional balance measure for assessing and predicting smoking status. Journal of personality and social psychology. 1985 May;48(5):1279.

29. Girma E, Assefa T, A D. Cigarette smokers' intention to quit smoking in Dire Dawa town Ethiopia: an assessment using the Trans theoretical Model. BMC Public Health. 2010 10(1):320

30. Abdelwahab SI, Alsanosy RM, Rahim BE, Mohan S, Taha S, Mohamed Elhassan M, El-Setouhy M. Khat (Catha edulis Forsk.) dependence potential and pattern of use in Saudi Arabia. BioMed research international. 2015;2015.

31. Kassim S, Islam S, Croucher R. Validity and reliability of a Severity of Dependence Scale for khat (SDS-khat). Journal of ethnopharmacology. 2010 Dec 1;132(3):570-7.

32. Kassim S, Rogers N, Leach $\mathrm{K}$. The likelihood of khat chewing serving as a neglected and reverse 'gateway'to tobacco use among UK adult male khat chewers: a cross sectional study. BMC Public Health. 2014 Dec 1;14(1):448.

33. Begum S, Bogosian A, McBain H. The experiences of people who quit khat and the health care professionals who support them. Addiction and Health. 2019 Dec 1;11(4):243-55.

34. Prochaska JO, Goldstein MG: Process of smoking cessation: Implications for clinicians. Clinics in Chest Medicine 1991, 12(4):727-735.

35. DiClemente C, Delahanty J, Jean F, Earley M, Garay M, Preston G, Meredith H, Angela P, Dan R, Kristina S, Onna V, Katherine W: health and addictive behaviors: investigating transtheoretical solutions, Transtheoretical model of behavior change Measures. 1994 
[http://www.umbc.edu/psyc//habits/content/ttm_measures/index.html]. accessed on September 30, 2008

\section{Tables}

Table 1: Socio demographic characteristics of Khat chewers in Gondar city, north west Ethiopia; 2019 $(n=605)$. 
Socio demographic characteristics

Sex

\begin{tabular}{|c|c|c|c|}
\hline & Female & 102 & 16.9 \\
\hline \multirow[t]{4}{*}{ Age in years } & $18-24$ & 200 & 33.1 \\
\hline & $25-29$ & 159 & 26.3 \\
\hline & $30-34$ & 106 & 17.5 \\
\hline & 35 and above & 140 & 23.5 \\
\hline \multirow[t]{4}{*}{ Religion } & Christian & 377 & 62.3 \\
\hline & Muslim & 191 & 31.6 \\
\hline & Protestant & 22 & 3.6 \\
\hline & Other (Catholic, no religion) & 15 & 2.5 \\
\hline \multirow[t]{4}{*}{ Ethnicity } & Amhara & 513 & 84.8 \\
\hline & Tigrie & 38 & 6.3 \\
\hline & Oromo & 37 & 6.1 \\
\hline & Other (Kimant, Gurage, Sidama) & 17 & 2.8 \\
\hline \multirow[t]{5}{*}{ Educational status } & Can't read \& write & 30 & 5.0 \\
\hline & Read \& write & 28 & 4.6 \\
\hline & Primary education & 55 & 9.1 \\
\hline & Secondary education & 222 & 36.7 \\
\hline & Diploma \& above & 270 & 44.6 \\
\hline \multirow[t]{6}{*}{ Occupation } & Government employee & 89 & 14.7 \\
\hline & Merchant & 132 & 21.8 \\
\hline & Self-employee & 93 & 15.4 \\
\hline & Student & 85 & 14.0 \\
\hline & Job seeker & 163 & 26.9 \\
\hline & Other (driver, Guard) & 43 & 7.1 \\
\hline \multirow[t]{3}{*}{ Marital status } & Single & 384 & 63.5 \\
\hline & Married & 174 & 28.8 \\
\hline & Divorced & 21 & 3.5 \\
\hline
\end{tabular}

\section{Frequency Percent}

$503-83.1$

Male

(2)




\begin{tabular}{clcc} 
& Other (separated, widowed) & 26 & 4.1 \\
\hline Monthly income in birr & $<2000$ & 302 & 49.9 \\
\cline { 2 - 4 } & $2000-3500$ & 134 & 22.1 \\
\hline & $>3500$ & 169 & 28.0
\end{tabular}

Table 2: Process of change and self-efficacy of stopping khat chewing among khat chewers in Gondar city, northwest Ethiopia; 2019 ( $n=605)$. 


\begin{tabular}{|c|c|c|c|}
\hline \multicolumn{2}{|l|}{ Variable } & \multirow{2}{*}{$\begin{array}{l}\text { Frequency } \\
292\end{array}$} & \multirow{2}{*}{$\begin{array}{l}\text { Percent (\%) } \\
48.3\end{array}$} \\
\hline Consciousness raising & Low & & \\
\hline & Medium & 53 & 8.8 \\
\hline & High & 260 & 43.0 \\
\hline \multirow[t]{3}{*}{ Dramatic relief } & Low & 273 & 45.1 \\
\hline & Medium & 49 & 8.1 \\
\hline & High & 283 & 46.8 \\
\hline \multirow[t]{3}{*}{ Self-reevaluation } & Low & 206 & 34.0 \\
\hline & Medium & 34 & 5.6 \\
\hline & High & 365 & 60.3 \\
\hline \multirow[t]{3}{*}{ Social liberation } & Low & 215 & 35.5 \\
\hline & Medium & 67 & 11.1 \\
\hline & High & 323 & 53.4 \\
\hline \multirow[t]{3}{*}{ Environmental reevaluation } & Low & 190 & 31.4 \\
\hline & Medium & 37 & 6.1 \\
\hline & High & 378 & 62.5 \\
\hline \multirow[t]{3}{*}{ Self-efficacy } & Low & 308 & 50.9 \\
\hline & Medium & 21 & 3.5 \\
\hline & High & 276 & 45.6 \\
\hline \multirow[t]{3}{*}{ Decisional balance } & Negative decisional balance & 347 & 57.4 \\
\hline & Undecided & 26 & 4.3 \\
\hline & Positive decisional balance & 232 & 38.5 \\
\hline \multirow[t]{3}{*}{ Khat dependency } & Low & 310 & 51.2 \\
\hline & Medium & 32 & 5.3 \\
\hline & High & 263 & 43.5 \\
\hline
\end{tabular}

Table 3: Multivariable analysis $(\mathrm{p}<0.05,95 \% \mathrm{Cl})$ for associated factors with intention to stop Khat chewing among Khat chewers in Gondar city, northwest Ethiopia; 2019. 


\begin{tabular}{|c|c|c|c|c|c|}
\hline \multirow[t]{2}{*}{ Variable } & \multirow[t]{2}{*}{ Category } & \multicolumn{2}{|c|}{$\begin{array}{l}\text { Intention to stop khat } \\
\text { chewing }\end{array}$} & \multirow[t]{2}{*}{$\mathrm{COR}, 95 \% \mathrm{Cl}$} & \multirow[t]{2}{*}{$\mathrm{AOR}, 95 \% \mathrm{Cl}$} \\
\hline & & Yes & No & & \\
\hline \multirow[t]{4}{*}{ Age at start of khat chewing } & $\leq 15$ & 22 & 32 & 1 & 1 \\
\hline & $16-20$ & 243 & 107 & $\begin{array}{l}2.3(1.8- \\
2.9)\end{array}$ & $3.2(1.5-6.9)$ \\
\hline & $21-25$ & 96 & 34 & $\begin{array}{l}2.8(1.9- \\
4.2)\end{array}$ & $2.8(1.1-6.9)$ \\
\hline & $\geq 26$ & 58 & 13 & $\begin{array}{l}4.4(2.4- \\
8.1)\end{array}$ & $\begin{array}{l}4.8(1.5- \\
15.5) *\end{array}$ \\
\hline \multirow{4}{*}{$\begin{array}{l}\text { Frequency of additional } \\
\text { drug use }\end{array}$} & Sometimes & 96 & 30 & 1 & 1 \\
\hline & 1-3 days & 67 & 24 & $\begin{array}{l}2.8(1.8- \\
4.5)\end{array}$ & $\begin{array}{l}0.51(0.2- \\
1.2)\end{array}$ \\
\hline & 4-6 days & 76 & 30 & $\begin{array}{l}2.5(1.7- \\
3.9)\end{array}$ & $\begin{array}{l}0.63(0.26- \\
1.5)\end{array}$ \\
\hline & Day to day & 84 & 53 & $\begin{array}{l}1.6(1.1- \\
2.2)\end{array}$ & $\begin{array}{l}0.37(0.16- \\
0.8) *\end{array}$ \\
\hline \multirow[t]{3}{*}{ Khat dependency } & Low & 222 & 88 & 1 & 1 \\
\hline & Medium & 20 & 12 & $\begin{array}{l}1.7(0.8- \\
3.4)\end{array}$ & $\begin{array}{l}0.72(0.25- \\
2.0)\end{array}$ \\
\hline & High & 177 & 86 & $\begin{array}{l}2.5(2.0- \\
2.7)\end{array}$ & $\begin{array}{l}0.61 \\
(0.38-.9) *\end{array}$ \\
\hline \multirow[t]{3}{*}{ Environmental Reevaluation } & Low & 87 & 101 & 1 & 1 \\
\hline & Medium & 28 & 10 & $\begin{array}{l}2.7(1.3- \\
5.6)\end{array}$ & $2.0(.78-5.4)$ \\
\hline & High & 302 & 77 & $\begin{array}{l}4.0(3.1- \\
5.2)\end{array}$ & $1.9(1.1-3.3)$ \\
\hline \multirow[t]{3}{*}{ Self-Reevaluation } & Low & 94 & 111 & 1 & 1 \\
\hline & Medium & 25 & 12 & $\begin{array}{l}2.4(1.1- \\
5.0)\end{array}$ & $1.6(0.6-4.2)$ \\
\hline & High & 298 & 65 & $\begin{array}{l}4.6(3.5- \\
6.0)\end{array}$ & $2.8(1.6-5.0)$ \\
\hline \multirow[t]{3}{*}{ Social Liberation } & Low & 110 & 104 & 1 & 1 \\
\hline & Medium & 42 & 27 & $\begin{array}{l}1.6(1.0- \\
2.6)\end{array}$ & $1.1(.53-2.3)$ \\
\hline & High & 265 & 57 & $\begin{array}{l}4.7(3.5- \\
6.2)\end{array}$ & $\begin{array}{l}1.8(1.01- \\
3.1) \star\end{array}$ \\
\hline
\end{tabular}


*Statistically Significant

Page $17 / 17$ 